\title{
ENTRE DIREITO, ECONOMIA E POLITTICA - AS CONTRIBUICÕES DA CIÊNCIA DO ESTADO ALEMÃ (STAATSWISCHENCHAFT) PARA O SUR GIMENTO NO SÉCULO XIX DE UMA NOVA CIÊNCIA DO DIREITO
}

\begin{abstract}
BETWEEN LAW, ECONOMY AND POLITICS - THE CONTRIBUTIONS OF THE GERMAN SCIENCE OF THE STATE (STAATSWISCHENCHAFT) FOR THE EMERGENCE OF A NEW LEGAL SCIENCE IN THE 19TH CENTURY

ENTRE EL DERECHO, LA ECONOMÍA Y LA POLÍTICA - LAS CONTRIBUCIONES DE LA CIENCIA DEL ESTADO ALEMANA (STAATSWISCHENCHAFT) PARA EL SURGIMIENTO EN EL SIGLO XIX DE UNA NUEVA CIENCIA DEL DERECHO
\end{abstract}

Alfredo Copetti Neto ${ }^{1}$

Marcelo Andrade Cattoni de Oliveira ${ }^{2}$

Para Gilberto Bercovici

RESUMO

O ensaio trata das contribuições da Ciência do Estado alemã (Staatswischenchaft), especificamente aquela desenvolvida em Göttingen, formada pelas pesquisas históricas sobre o direito de propriedade, para a formação de uma nova Ciência do direito. (R)estabelece-se a afinidade fundamental do direito com a economia e de ambos com a política, todos, por assim dizer, ressignificados em relação ao aspecto racional/natural clássico que os estabelecia. Forma-se, diante disso, o que se pode chamar de primeiro movimento Law and Economics, uma mixagem das Escolas Históricas alemã e inglesa e, mais adiante, do Institucionalismo americano.

PALAVRAS-ChAVES: Ciência do Estado. Ciência do Direito. Law and Economics.

\begin{abstract}
The essay deals with the contributions of German Science of the State (Staatswischenchaft), specifically the one developed in Göttingen, formed by the historical research on the right of property for the formation of a new Legal Science. The fundamental affinity of the law, economics and politics is (re)established, and all are reinterpreted in relation to the rational/natural classic aspect that established them. Based on this, what might be called the first Law and Economics movement was formed - a mixing of the English and German Historical Schools - and later, American Institutionalism.

1 Mestre em Direito Público pelo Programa de Pós-graduação em Direito da Unisinos. Doutor em Teoria do Direito e da Democracia pela Università degli Studi di Roma III (revalidado UFPR). Cumpre estágio de Pós-doutorado júnior (PDJ/CNPQ) no Programa de Pós-graduação em Direito da Unisinos. Professor Convidado do Mestrado em Direitos Humanos da Unijuí.

2 Mestre e Doutor em Direito Constitucional pelo Programa de Pós-graduação em Direito da UFMG. Estágio Pós-doutoral com bolsa CAPES em Teoria e Filosofia do Direito na Università degli Studi di Roma III. Professor Associado II da Faculdade de Direito da UFMG.
\end{abstract}


KEYWORDS: Science of the State. Legal Science. Law and Economics.

RESUMEN

Este ensayo trata de las contribuciones de la Ciencia del Estado alemana (Staatswischenchaft), específicamente aquella desarrollada en Göttingen, formada por las investigaciones históricas sobre e derecho de propiedad, para la formación de una nueva Ciencia del Derecho. Se (re)establece la afinidad fundamental del derecho con la economía y de ambos con la política, todos, por así decir, resignificados en relación al aspecto racional/natural clásico que los establecía. Se forma, ante esta situación, lo que se puede denominar primer movimiento Law and Economics, una mezcla de las Escuelas Históricas alemana e inglesa y, más tarde, del Institucionalismo americano.

PALABRAS CLAVE: Ciencia del Estado. Ciencia del Derecho. Law and Economics.

\section{INTRODUÇÃO}

O que sustentou, expressamente, a diferença e ao mesmo tempo estimulou a relação entre direito e economia política, por um lado, tem que ver com as particulares mudanças vinculadas ao paradigma filosófico-científico em que se consolidaram as disciplinas; e, por outro, com as especificidades histórico-políticas, que estimularam o desenvolvimento daquele paradigma.

Com o advento da revolução racionalista ${ }^{3}$ - da qual se valeu também a revolução burguesa, cujo fundamento se estruturou no compasso da lei natural, supostamente garantidora de uma ordem perfeita, harmônica e justa ${ }^{4}$-, o pensamento filosófico-político se descolou de suas antigas amarras teológicas, possibilitando, assim, a diferenciação entre filosofia e ciência e, ainda, particularmente, elevando a economia política e o direito ao status de disciplinas autônomas.

Estimulada pelo aparecimento do capitalismo - cujo indício desde logo compreendeu Adam Smith ${ }^{5}$, na medida em que colocou as relações de troca como determinadas e estimuladas pelas relações de produção -, a economia assumiu as rédeas da sociedade civil e, respaldada pela ordem física e soberana do mundo, que também fora reconhecida naquele contexto como lei moral, enalteceu seu próprio funcionamento autônomo, orientado, de modo categórico, tanto contra o discurso teológicometafísico; como contra o discurso do poder político regulador do estado ${ }^{6}$.

A autoridade deixou de ser empossada, de forma sacra, pela graça de Deus e passou a ser instituída pela vontade dos membros do estado que, mediante a composição de uma assembleia geral, estabeleceram os pressupostos necessários para a expansão dos interesses de uma nova classe social: a burguesia?.

Nesses termos, a chamada economia clássica se colocou como economia política, identificandose como instrumento científico, mas também ideológico, que visava derrocar a hegemonia da classe dominante feudal, proclamando a liberdade de todos os indivíduos ${ }^{8}$. Liberdade essa que concebeu o estado nos termos de uma pura razão universal, combatente tanto do pecado original como do legislador divino - fundadores da ordem hierárquica teológica -, para colocar o homem como

3 BACON, Francis. Ensaios. 3. ed. Lisboa: Guimarães editores, 1992. DESCARTES, René. Discurso sobre o método. Bauru. Edipro, 1996.

4 NUNES, António José Avelãs. Uma Introdução à Economia Política. São Paulo: Quartier Latin, 2007, p. 16.

5 SMITH, Adam. La ricchezza delle nazioni. 2.ed. Roma: Newton Compton Editori, 2005. P. 78 e segs.

6 NUNES, António José Avelãs. op., cit., p. 14 e segs.

$7 \mathrm{BLOCH}$, Ernest. Diritto naturale e dignità umana. Torino: Giappichelli Editore, 2005, p. 49.

8 NUNES, António José Avelãs. op. cit., p. 14. MUSU, Ignazio. Pensiero economico e diritto. Più teorie economiche, ma terreni comuni. In: CIOCCA, Pierluigi; MUSU, Ignazio. (a cura di). Economia per il diritto. Torino: Bollatti Boringhieri, 2006, p. 52. 
homem livre, mas também como homem dos negócios, o empreendedor que surgiu como símbolo do progresso; o representante de uma nova era ${ }^{9}$.

Assim, o capitalismo dos clássicos ingleses, defendido como plano econômico do liberalismo ${ }^{10}$, ao contrário do que se compreendeu pelo senso comum, foi um forte instrumento para o desmantelamento do status quo mercantilista e representou, na sua essência, a crítica e o impedimento dos privilégios que eram concedidos pelo estado feudal aos grandes senhores da terra, representantes das práticas monopolistas à época ${ }^{11}$.

Significa dizer, portanto, que se o papel da economia política clássica era aquele de encontrar as leis naturais a serem aplicadas nas relações sociais econômicas; o papel do direito, não longe disso, resguardando e avocando bases jusnaturalistas, era somente o de preservar e possibilitar a ação harmônica das leis naturais que configuravam a economia ${ }^{12}$.

O direito determinado pelo paradigma jusnaturalista se assentava nas aspirações de um cognitivismo normativo - cuja pedra angular se expressava pela máxima: veritas, non auctoritas facit legem ${ }^{13}$, em que a validade jurídica dependia taxativamente do binômio racionalidade/justiça intrínseca de seus conteúdos -, que reconhecia como naturais e inatos os direitos de propriedade, de iniciativa econômica, de troca voluntária ${ }^{14}$.

Tal pressuposto representou uma forte carga heterônoma à fundamentação do direito, na medida em que se reconhecia a validade jurídica somente mediante critérios prévios estipulados pela filosofia política ${ }^{15}$, por sua vez estabelecida como a força de uma construção racional geral ${ }^{16}$, cuja legitimidade se traçava pela ordem natural e determinava os limites da antítese revelada pela dicotomia: liberdade - econômica - poder - do Estado ${ }^{17}$.

Economia e direito caminhavam, portanto, estreitamente vinculados ao paradigma filosóficopolítico subjacente a ambos. Porém tinham campos de atuação notadamente diversos: aquela, a economia - vista como análise científica da evolução econômica da sociedade ${ }^{18}$-, possibilitaria o progresso por meio das relações de produção capitalista, na medida em que conciliava a ideologia burguesa - reformadora - aos interesses das camadas populares; este, o direito - direito natural de caráter antropológico ${ }^{19}$-, disposto num sistema de normas pré-compreendidas como verdadeiras e/ou justas, estabelecidas mediante os critérios da ordem natural, servia à proteção e à garantia dos pressupostos necessários ao desenvolvimento da economia capitalista.

Nitidamente existiu uma simbiose político-filosófica e socioinstitucional que protagonizou o nascimento da relação entre as disciplinas direito e economia, isto é, o direito e o seu sistema de regras foi compreendido como pressuposto essencial à economia; uma condição imprescindível ao funcionamento do sistema econômico que, embora adotasse como técnica idônea aquela de sanções negativas, tinha, já no século XIX, funções assumidamente protetivas, além daquelas repressivas ${ }^{20}$.

Entretanto todo o otimismo empregado em direção à ordem natural do mercado, consubstanciada na ideia de um mundo contínuo, acelerado pelo progresso material e moral21, foi se tornando questionável na medida em que a burguesia foi assumindo o lugar de classe hegemônica.

9 BLOCH, Ernest. Op. cit., p.48 e segs.

10 LOCKE, John. The Works of John Locke in Nine Volumes. 12. Ed. London: Rivington, 1824. Em especial vol. 4. Disponível em: http://oll.libertyfund.org/title/763. Acesso em: 15/04/2009. BOBBIO, Norberto. Liberalismo e Democrazia. Milano: Simonelli Editore, 2006.

11 NUNES, António José Avelãs. op. cit., p. 20.

12 MUSU, Ignazio. op. cit., p.52.

13 FERRAJOLI, Luigi. Diritto e ragione: Teoria del garantismo Penale. 8. ed. Roma-Bari, 2004, p. 17.

14 MUSU, Ignazio. Op. cit., p.52.

15 FERRAJOli, Luigi. Principia iuris. Teoria del diritto e della democrazia. 2. Teoria della democrazia. Roma-Bari: Laterza, 2007, p. 32.

$16 \mathrm{BLOCH}$, Ernest. Op. cit., p.49.

17 BOBBIO, Norberto. Prefazione. In: FERRAJOLI, Luigi. Diritto e ragione, op. cit., p. VIII.

18 NUNES, António José Avelãs. op. cit., p.22.

19 HöFFE, Otfried. O que é justiça? Porto Alegre: Edipucrs, 2003, p.45.

20 BOBBIO, Norberto. Dalla struttura alla funzione. Nuovi studi di teoria del diritto. Bari: Laterza, 2007. p. 22. CAPPIELLO, Stefano. L'interazione tra economia e diritto. In: CIOCCA, Pierluigi; MUSU, Ignazio. op. cit., p. 71.

21 HOBSBAWM, Eric J. Il trionfo della borghesia. 1848-1875. 2. ed. Roma-Bari: Laterza, 2006, p.3. 
A classe burguesa, na medida em que se reconhecia detentora do poder político, paulatinamente fazia mais nítida a sua proposta ideológica. A revolução política, pela qual esperavam as massas populares, foi colocada em segundo plano. O termo revolução foi compreendido, a partir de então, como revolução industria/22, cujos pressupostos já estavam estabelecidos sob a base do capitalismo como sistema social definitivo em que as leis econômicas eram aquelas tracejadas pela suposta ordem natural23.

Embora a economia política clássica tivesse aglutinado em si a representação da estrutura econômica, do sistema científico, da teoria do desenvolvimento econômico e da teoria da política econômica, seu sistema de abstrações teve sucesso somente à época em que o capitalismo apareceu como a nova estruturação da economia. Entretanto, com o passar do tempo, aquelas mesmas abstrações que se mostravam propícias política e teoricamente começaram a se revelar inadequadas diante das mudanças qualitativas pelas quais passou o próprio sistema econômico ${ }^{24}$.

Dito de outro modo, como teoria do desenvolvimento econômico, cuja compreensão era essencialmente a-histórica, estabelecida mediante uma validade eterna, a economia clássica pôs em prejuízo a construção de uma dinâmica econômica; como teoria de política econômica, o classicismo, baseado na filosofia política de Locke, buscou guarida no direito natural de propriedade aplicando as especificidades da ordem natural aos fatos reais do mundo, e com isso causando um descompasso à possibilidade de interpretação igualitária da sociedade ${ }^{25}$.

Nesse sentido, com o aparecimento da consciência proletária, que marcou o início da luta de classes, acentuou-se radicalmente a cisão da economia política clássica como a ciência que estudava as relações econômicas entre os homens: a produção se destacou da proposta ideológica de progresso político; a economia política se tornou um artefato à defesa dos interesses da classe dominante ${ }^{26}$.

Reforma e revolução ${ }^{27}$ foram os termos encontrados à reestruturação ou à ruptura do sistema capitalista. O conflito, de qualquer forma, se mostrou inevitável, sobretudo pelas interpretações possibilitadas, dentro do próprio sistema, pelo aparecimento do utilitarismo, cuja cobrança se acentuava em direção da busca da igualdade entre o rico e o pobre, com base na proposta iniciada por Bentham e desenvolvida por seus seguidores ${ }^{28}$ de uma lei matemática de indiferença que visava favorecer a igual distribuição de riqueza na sociedade, de um lado; e pela consciência trazida à tona por Marx, que partindo da tradição clássica, pôs em evidência o caráter social do homem e a essência eminentemente exploradora do capitalismo, de outro ${ }^{29}$.

Formam-se, assim, por um vértice a crítica revolucionária estabelecida por Mar $x^{30}$, que colocou o escopo da economia política fora da análise da relação do homem com a natureza, mas como determinante para estabelecer a relação dos homens no processo de produção; por outro vértice, as reações dentro do próprio sistema liberal-capitalista em que as teorias da economia vulgar ${ }^{31}$ possibilitariam instrumentos para alcançar uma pretensa reforma da economia política clássica.

A discussão tomou rumos diferentes e se estabeleceu em outro elemento, razão da economia e do direito: a fundamentação do direito de propriedade ${ }^{32}$, preço pago pelo capitalismo à sua manutenção, que passou a se destacar de suas raízes absolutas e a compactuar de discursos tanto políticos como econômicos. O direito estabelecia regras, a economia influía político-juridicamente.

22 Idem. Ibidem, p. 4.

23 NUNES, António José Avelãs. op. cit., p. 28.

24 ROLL, Eric. A History of Economic Thought. Oxford: Alden Press, 1973, p. 199.

25 ROLL, Eric. op. cit., p. 200-1.

26 NUNES, António José Avelãs. op. cit., p.24-5. MARX, Carl. Il capitale. Critica dell'economia politica. 4. ed. Roma: Newton, 2008, em especial: Poscritto alla seconda edizione, p. 45.

27 ROLL, Eric. op. cit., p. 199.

28 MILL, John. The Principles of Political Economy with some of their applications to social philosophy. Disponível online em: http://www.ecn.bris.ac.uk/het/mill/prin.htm. Em especial: Book 2 - Distribution Chapter 1 - Of Property, p. 138 e segs. Ver, também, os críticos socialistas ingleses na obra de ROLL, Eric. op. cit., p. 245-50.

29 MARX, Karl. Para uma crítica da economia política. Disponível on-line em: LivrosGrátis/paraumacritica.htm.

30 MARX, Karl. Para uma crítica da economia política, op. cit.

31 Idem, Ibidem.

32 RODOTÀ, Stefano. Il diritto terribile. Studi sulla proprietà privata. 2. ed. Bologna: Mulino, 1990, p. 16 e segs. 
Foi nesse patamar que se edificaram novos estudos para apontar que os lugares iniciais da marcha que levou às aspirações e ao desencadeamento do movimento da chamada Análise Econômica do Direito têm referências bem mais antigas, que ultrapassaram o Atlântico e que chegaram à parte continental da Europa ${ }^{33}$.

\section{O EXEMPLO PRIVILEGIADO DA CIÊNCIA DO ESTADO ALEMÃ (STAATSWISSENSCHAFT) PARA UMA NOVA CIÊNCIA DO DIREITO (NEW SCIENCE OF LAW)}

Em meados do Século XIX, na Europa, existiam estudos que pretendiam criar uma melhor forma de cognição para o direito, em que o sistema jurídico seria capaz de compreender, na medida em que utilizassem no seu interior conceitos e métodos econômicos, os motivos pelos quais as provisões legais - voltadas à produção e ao consumo de bens e serviços, isto é, ao direito contratual, ao trabalho humano e, especialmente, ao direito de propriedade - adquiriam formas específicas de acordo com o tempo e o lugar nos quais estavam sendo tracejadas e, a partir disso, impunham à organização política e social determinadas posturas de conduta ${ }^{34}$.

Esse era o ponto fundamental exposto pela New Science of Law, da qual faziam parte a Escola Histórica inglesa e a alemã e, ainda, posteriormente, a American Institutionalist School. Uma corrente inicialmente desenvolvida entre os economistas alemães e que também ganhou corpo nas escolas jurídicas, a partir da influência das obras de Karl Marx, datadas do final do século XIX ${ }^{35}$.

De forma precisa, a reviravolta articulada pela New Science, que meticulosamente reestruturou o modo de pensar as implicações existentes entre direito e economia, deu-se em virtude da peculiar contribuição protagonizada pela German Staatswissenschaft Tradition ${ }^{36}$, cujo precursor, Herman Conring ${ }^{37}$, já no século $\mathrm{XV}$, defendia a necessidade de uma concepção histórica e do adequado estudo dos sistemas políticos para a elaboração do raciocínio jurídico ${ }^{38}$.

O pensamento evolucionista ${ }^{39}$, desenvolvido nas universidades alemãs, fortaleceu a percepção da inevitável mutabilidade das estruturas sociais $e$, nesse sentido, precipitou a necessidade da aproximação das disciplinas - direito e economia - que, inicialmente, foram associadas ao currículo acadêmico da Staatswissenschaft - Ciência do Estado ${ }^{40}$.

A Staatswissenschaft foi uma doutrina que cresceu exponencialmente na Universidade de Göttingen - na qual também se difundiu a moderna concepção de Staatsrecht, Staatenkunde e Statistik - e era praticada sob uma visão enciclopédica, comparativa e histórica, que tinha na clareza cartesiana e na meticulosidade da historiografia convencional os seus pontos chaves de efetivação ${ }^{41}$.

As orientações de Göttingen ${ }^{42}$ trouxeram o arcabouço da história social como suporte teórico ao desenvolvimento da economia política, impregnando-a de um caráter mais empírico e humanista.

Nesse sentido, a ciência do Estado, que originalmente era fundada na Filosofia do Espírito

33 PEARSON, Heath. Origins of Law and Economics: the economists' New Science of Law, 1830-1930.

Cambridge: Cambridge University Press, 1997. MACKAAY, Ejan. History of Law and Economics. In:

BOUCKAERT, Boudewijn and DE GEEST, Gerrit, Encyclopedia of Law and Economics, Volume I. The History and Methodology of Law and Economics, Cheltenham, Edward Elgar, 2000.p. 69-71.

34 PEARSON, Heath. op. cit. p. 6.

35 MACKAAY, Ejan. op. cit. p.69.

36 PEARSON, Heath. op. cit, p.21.

37 WIEACKER, Franz. A history of private Law in europe with particular reference to Germany. NY: Oxford University Press, 1995, p.160-1.

38 PEARSON, Heath. op. cit. p. vii e 21.

39 BURROW. J. W. Evolution and Society. Cambrigde: Cambridge University Press, 1966.

40 PEARSON, Heath. op. cit. p. VII. BARROW, Clyde. When Political Science Was Not a Discipline: Staatswissenschaft and the Search for a Method of Economic Interpretation. Annual meeting of the Western Political Science Association. Marriott Hotel, Portland, Oregon, Mar 11, 2004. Disponível em: http://www.allacademic.com/meta/p88082_index.html.

41 PEARSON, Heath. op. cit. p. 21.

42 IGGERS, George G. New Directions in European Historiography. Middletown: Wesleyan University Press, 1975, p. 15. 
Objetivo de Hegel, sofreu uma mudança intelectual e foi rearticulada de acordo com as explicações provenientes da sua relação com as mudanças econômicas ${ }^{43}$.

O Estado, sob esse ponto de vista, estava progressivamente tomando o lugar central da evolução social, sendo que a evolução do Estado era compreendida de acordo com a evolução do direito; e este, por sua vez, encontrava nas transformações econômicas o seu ponto explicativo ${ }^{44}$.

A ciência política, articulada como ciência do Estado e sublinhada pelos discursos históricos que se compunham na compreensão do Estado como evolução política, buscava estabelecer o seu fundamento na relação entre política, direito e economia para que fosse possível, a partir dessa afinidade, a estruturação de uma identidade substancia/45, consubstanciada em um método científico único ${ }^{46}$.

Entre aqueles que se lançaram nessa nova concepção acadêmica, é necessário destacar o papel desenvolvido por Justus Möser ${ }^{47}$, responsável pela fundação da German Historical School of Economics, ainda no século XVIII ${ }^{48}$. Nesse sentido, o discurso historicizado das ciências sociais, que encontrou na economia política o seu meio de propagação e que se fortaleceu na disciplina da Staatswissenschaft, foi ampliado pelas investigações de Georg Hanssen, a respeito da necessária consideração de uma racionalidade limitada; Friedrich List, que difundiu a importância das instituições públicas ao desenvolvimento da força de produção individual; e Wilhelm Roscher, cuja particularidade se deu na constatação de que cada especificidade histórica se desenvolvia como um cíclico fundamento, influenciando a organização e a riqueza das nações ${ }^{49}$.

Cabe frisar, de toda forma, o importante deslocamento ocorrido na primeira metade do século XIX, haja vista que as questões relativas à análise do direito até então, partindo-se do ponto de vista da teoria econômica, eram deixadas em segundo plano.

Como anteriormente referido, a teoria econômica naquele tempo se limitava a compreender os efeitos causados no sistema econômico pelo sistema jurídico. A premissa considerada era: o direito existe e deve ser respeitado ${ }^{50}$.

Três conjunturas impuseram forte influência à manutenção dessa premissa: a) a primeira, determinada pelos economistas clássicos, que desvinculavam os estudos do progresso e da riqueza sociais das questões relativas às origens ou à legitimidade do direito ${ }^{51} ; b$ ) a segunda, em conformidade com a primeira, que reconhecia o direito como um dado natural, associado à normatividade de critérios éticos; c) a terceira, ainda mantendo um critério de ciência ética de direitos, porém se desvinculando de uma razão metafísica natural e, assim, estabelecendo o direito como um artefato social, porém um problema normativo pertencente apenas à ciência moral ${ }^{52}$.

Entretanto, a partir daquelas novas investigações motivadas pelos economistas alemães, que deslocaram o discurso da economia política para explicar historicamente o funcionamento das regras sociais em geral, e do direito em particular, de um lado; e das imbricações produzidas pela revolução política de $1848^{53}$, em que o movimento proletário confrontou a hegemonia do liberalismo moderno, por outro, foi que a New Science of Law apareceu como possibilidade de desenvolver uma distinta ciência de direitos, ou seja, uma concepção diversa daquela até então vigente - e defendida ainda pela ordem liberal -, deixando de invocar argumentos de direitos naturais do homem, cuja ênfase era colocada em compasso com uma concepção de justiça intrínseca, para se prender à ideia de progresso econômico como valor social, sem abrir mão, contudo, de uma proposta conservadora ao identificar tal valor social na manutenção do status quo ${ }^{54}$.

43 BARROW, Clyde. op. cit., p. 10.

44 BARROW, Clyde. op. cit., p. 10 e segs.

45 BARROW, Clyde. op. cit., p. 10 e segs.

46 BARROW, Clyde. op. cit., p. 10 e segs.

47 WIEACKER, Franz. op. cit., p. 283.

48 PEARSON, Heath. op. cit., p. 22.

49 PEARSON, Heath. op. cit., p. 25.

50 PEARSON, Heath. op. cit. p. 7.

51 SAY, Jean-Baptiste. A Treataise on Political Economy; or the Production, Distriution, and Consumption of Wealth. Canadá: Batoche Books, 2001, p. 30 e segs.

52 PEARSON, Heath. op. cit. p. 14-8.

53 MARX, Karl; ENGELS, Friedrich. Manifesto do partido comunista. Disponível em: file:///Cl/site/ livros_gratis/manifesto_comunista.htm, 2001.

54 PEARSON, Heath. op. cit. p. 24. 
A fundamental assertiva colocada pela New Science era aquela em que uma solução econômica adequada, cujo objetivo visasse analisar o problema da produção, do consumo, do contrato ou da propriedade, deveria ter como pressuposto necessário o reconhecimento de regras, além de outras variáveis econômicas ${ }^{55}$.

Segundo a tese defendida pelo movimento, o direto e, consequentemente, a propriedade privada eram apontados historicamente e desempenhavam uma função diferente em cada tipo de sociedade ${ }^{56}$; isto é, o sistema jurídico era contingente e o pressuposto de sua adequação se vinculava a uma determinada condição econômico-cultural ${ }^{57}$.

Nesse sentido, qualquer alteração e/ou deslocamento referentes aos direitos de propriedade, necessariamente, trariam consequências inevitáveis às condições econômicas de um modo geral.

O progressivo ajuste metodológico pelo qual passou a economia política, para que fosse possível trazer ao campo da análise econômica uma ampla exploração das relações sociais, que possibilitasse, inclusive, o estudo das origens das forças jurídicas - na perspectiva de um fenômeno histórico, dependente da composição entre tempo e lugar, instável, determinada como artefato da cultura - , não somente adequou as pesquisas em direito, economia e política sob um único enfoque, mas fortaleceu a ideia de que a propriedade surge como consequência da lei, não como sua causa ${ }^{58}$.

A guinada teórica estimulada pela Escola Histórica alemã se difundiu por diferentes partes da Europa, na medida em que serviu para reestruturar substancialmente a ordem liberal; ou seja, rompeu com o fundamento de sacralidade da propriedade privada, pois em contradição com a própria evolução da história, e rearticulou os vínculos liberais em conformidade com os argumentos de progresso econômico59.

Dito de outra forma, com o reconhecimento das estritas diversidades nacionais, sobretudo no que diz respeito às questões alusivas aos regimes de propriedade privada, mostrou-se insuficiente aos sistemas legais unir o fundamento do direito de propriedade aos princípios de justiça intrínseca dos direitos individuais.

Foi bem mais adequado, sob esse aspecto, reconhecer a total diversidade da origem do direito de um modo geral e, assim, desvinculá-lo de um fundamento metafísico único de justiça natural, para justificá-lo em conformidade com o fim comum de uma utilidade social ${ }^{60}$.

Sob o argumento de não mais fundamentar as origens do direito de propriedade, mas sim de justificar suas finalidades sociais, foi que a New Science of Law promoveu o desenvolvimento de uma historiografia científica como meio de possibilitar a compreensão do sistema social como um todo, cuja concepção se alastrou pelo decorrer do século XIX, primeiramente na Alemanha, depois na Inglaterra, numa visão comparativa e antropológica ${ }^{61}$ e, ainda, pelo enfoque institucionalista, nos Estados Unidos ${ }^{62}$.

Assim, na medida em que as inovações propostas pela Escola Histórica alemã foram sendo cultivadas, alguns círculos intelectuais foram sendo influenciados, aderindo e, desse modo, avolumando cada vez mais as perspectivas de um amplo intercâmbio entre o direito e a economia política à formação de uma New Science of Law, na medida em que se iniciou a compreensão de que o direito era contingente, vinculado sobretudo às condições sociais em que se desenvolvia.

Cabe salientar, com relação ao acima exposto, que o desenvolvimento da Escola Histórica alemã teve propensões no âmbito da economia à influência do direito pelo suporte recebido pela construção da Teoria do Estado desenvolvida na Alemanha ${ }^{63}$ a partir da ideia de direito público

5 PEARSON, Heath. op. cit, p. 6.

56 WIEACKER, Franz. op. cit., p. 284.

57 MACKAAY, Ejan. op. cit. p.69.

58 PEARSON, Heath. op. cit, p.25.

59 PEARSON, Heath. op. cit, p.25.

60 PEARSON, Heath. op. cit, p.26.

61 Sobretudo pela visão de Maine, mais adiante elucidada.

62 PEARSON, Heath. op. cit, p.25. MERCURO, Nicholas; MEDEMA, Steven G. Economicsand the Law: from Posner to Post-Modernism. New Jersey:Princeton University Press, 1999, p.101-8.

63 Sobre o Estado de Direito que se desenvolveu na Alemanha ver: COSTA, Pietro. Lo Stato di diritto: un'introduzione storica. In: COSTA, Pietro; ZOLO, Danilo. Lo stato di diritto. Storia, teoria e critica. 3. ed. Milano: Feltrinelli, 2006, p. 89-160. GOZZI, Gustavo. Democrazia e diritti. Germania: dallo 
subjetivo ${ }^{64}$, em que a base da autoridade estatal fundava a - e não era fundada pela - concepção de liberdade.

Foram muito diferentes os amálgamas que se refletiram no poder público pela Revolução alemã de 1848 em comparação àquela francesa de 1789, na medida em que esta, com base nos direitos fundamentais elencados em sua declaração, fez por bem vincular o movimento do Estado à tutela dos direitos do homem; enquanto aquela compreendeu que o estado servia para modificar a esfera do exercício dos direitos privados. Na verdade, a concepção do direito estava na lei do Estado, haja vista que a liberdade se fundamentava pelo limite estabelecido na própria lei. Era, em resumo, uma liberdade posta sobre a base da autoridade do Estado65.

\section{DIREITO, ECONOMIA E POLÍTICA DIANTE DE REFORMAS PARADIGMÁTICAS SOCIOINSTITUCIONAIS: AS RAÍZES ECONÔMICAS DA NOVA CIÊNCIA DO DIREITO (NEW SCIENCE OF LAW)}

A reviravolta que provocou a passagem de um Estado de Direito a um Direito do Estado ${ }^{66}$ enalteceu e levou à era de ouro a proposta da New Science of Law. O extraordinário desenvolvimento econômico da época repercutiu na compreensão de que o direito era o Direito do Estado, conjugando Estado, direito, política e economia. O aspecto paradoxal que se deve destacar, entretanto, é que os membros da Escola Histórica da Economia, formados, sobretudo, em Göttingen, eram liberais e não tinham visões políticas reacionárias; enquanto a Escola Histórica do Direito defendia fortemente a ideia de conservação do status quo ${ }^{67}$.

Na verdade, existia um descompasso em relação à compreensão do próprio método histórico, cujos fundamentos, obviamente, se direcionavam e levavam a fins diversos.

Especificamente, os estudos de Friedrich Carl von Savigny ${ }^{68}$ provocaram um abrandamento na concepção de economia política de Göttingen, enquanto as ideias de Rudolf von Jhering ${ }^{69}$ - este último já na segunda fase de seu pensamento - contribuíram em certo grau para a expansão daquela ideia historicista.

De toda a forma, para ambos, a ordem jurídica não era um fenômeno abstrato e fixo, mas uma variável que se relacionava e coexistia com o progresso de diferentes fatores sociais ${ }^{70}$; ela era compreendida e desenvolvida em conformidade com a tradição de uma determinada sociedade, o que não significava, portanto, que pudesse ser transferida e aplicada, de forma indistinta e absoluta, a qualquer estágio em que se encontrasse a civilização.

A tese organicista, pela qual a corrente histórica ganhou forma - que buscava no direito vivo, orgânico e sempre em evolução uma nova base para a racionalidade jurídica -, não foi rechaçada pela Escola Histórica do Direito; muito ao contrário, essa passou a sustentar a ratio iuris histórica como o fundamento legitimador da ordem jurídica.

Inclusive Savigny, que foi um dos grandes responsáveis por essa construção, não deixou de vincular o direito à expressão da cultura que se desenvolvia em conformidade com o espírito de cada

Stato di diritto alla democrazia costituzionale. 2. ed. Roma-Bari: Laterza, 2003, p. 35 e segs. RITTER, Gerhard A. Storia dello Stato sociale. 2. ed. Roma-Bari: Laterza, 2007, p. 61 e segs.

64 GERBER, Carl Friedrich Wilhelm Von. Sui diritti pubblici e Lineamenti di diritto pubblico tedesco. In: Diritto pubblico. Milano: Giuffrè, 1971, p. 3-87 e 89-213. Ver, por todos, a crítica de FERRAJOLI, Luigi. Diritto e ragione..., op. cit., p. 955. Também a elucidação de GOZZI, Gustavo. Democrazia e diritti..., op. cit., p. 46.

65 GOZZI, Gustavo. Democrazia e diritti..., op. cit., p. 34.

66 GOZZI, Gustavo. Democrazia e diritti..., op. cit., p. 46. FIORAVANTI, Maurizio. Costituzione. Bologna: Il Mulino, 1999, p. 118 e segs. MATTEUCCI, Nicola. Organización del Poder y Libertad: Historia del Constitucionalismo Moderno. Madrid: Trotta, 1998, p. 253 e segs.

67 ROLL, Eric. A history of Economic Thought, op. cit., p. 305.

68 SAVIGNY, Friedrich Carl von. La Vocazione del nostro Secolo per la Legislazione e la Giurisprudenza. Bologna: Forni, 1968, p. 201 e segs.

69 IHERING, Rudolf Von. El espiritu del Derecho Romano. Oxford: Oxford University Press, 2001. IHERING, Rudolf Von. A luta pelo direito. 5. ed. São Paulo: RT, 2008.

70 INGRAM, John Kells. A History of Political Economy, 1888, p. 80. Disponível em: http://www. dominiopublico.gov.br/pesquisa. 
povo - Volksgeist ${ }^{71}$-e de adequá-lo, em certa parte ${ }^{72}$, às vertentes românticas que impregnavam o ambiente germânico à época.

Sendo o direito criado espontaneamente pelo Volksgeist, o pensador alemão refutava a possibilidade de uma imediata codificação do direito germânico. Segundo ele, existia uma interna incompatibilidade entre o direito - produto espontâneo do espírito do povo - e a expressão do arbítrio a priori do poder soberano, naquele caso, o poder do legislador ${ }^{73}$.

Pode-se afirmar, amplamente, que a Escola Histórica do Direito se opôs à ideia de codificação vinculada ao positivismo exegético francês por entender que o racionalismo jusnaturalista iluminista do século XVIII não se mostrava capaz de se sustentar como ciência. Era muito difícil, conforme os doutrinadores históricos, vincular o caráter científico do direito a uma autonomia racional universal que pudesse ser modificada a cada simples expressão da vontade do legislador ${ }^{74}$.

As discussões a respeito da codificação do direito alemão, que resultaram na célebre disputa travada entre Thibaut - representante do jusracionalismo tardio - e Savigny - vinculado à ideia de um jusracionalismo historicista -, foram uma espécie de debate quanto aos fundamentos racionais do direito. Aquele defendendo a codificação que supostamente traria, a partir dos princípios formulados segundo a razão e aplicáveis universalmente, unificação política e jurídica à Alemanha; este, em contrapartida, se valia do argumento de que a codificação imobilizaria o direito, cujo desenvolvimento se daria somente pelo estímulo à cultura jurídica do povo alemão ${ }^{75}$.

Mostrou-se evidente, de todo modo, a nova força que se ergueu em conformidade com a proposta de sistematização histórica dos estudos jurídicos promovida pelo movimento, haja vista que, pelas mãos de Savigny, se conseguiu retardar em cerca de cem anos a promulgação do Código Civil Alemão, comparando-o àquele francês ${ }^{76}$.

Claramente, os historicistas jurídicos convergiam na opinião de que a sociedade ainda não se encontrava apta à codificação. Para a Escola Histórica, aperfeiçoar o direito à sociedade que emergia e reformar a ordem legal tinha de acontecer preliminarmente a qualquer hipótese de codificação.

Porém Savigny, particularmente, sustentava que essa adaptação e reforma do direito tinha de levar em conta os estudos aprofundados feitos pela tradição romana para, somente depois, adaptála às especificidades alemãs.

O costume, então, foi definido como a fonte do direito por excelência, cabendo à ciência jurídica apenas duas funções: a) compreender o contexto histórico, cuja finalidade seria exclusivamente a de determinar os sentidos normativos que deveriam gerir a convivência social - momento histórico; b) adequar a compreensão do momento histórico a conceitos jurídicos - momento científico ${ }^{77}$.

Surgem, nessa medida, os seguintes questionamentos: a) quando se fala de costume, de qual costume se fala? b) Esse momento científico não vai de encontro ao método histórico delineado e concebido como a grande reviravolta dada pelo movimento à época?

Todavia foi essa fixação a responsável pela ampliação de uma divergência interna que paulatinamente se formou entre os adeptos do método histórico em geral, ou seja, amarrar o momento histórico a conceitos jurídicos que já estariam previamente estabelecidos poria em risco o desenvolvimento orgânico do sistema social.

Além disso, valer-se das ideias delineadas pelo sistema clássico de direitos para projetar uma espécie de humanismo supranacional, afastando a demagogia da legislação e, assim, por outros

71 WIEACKER, Franz. op. cit.,p. 285.

72 WIEACKER, Franz. op. cit.,p. 286-7

73 ASCHERI, Mario. Introduzione storica al diritto moderno e contemporaneo: lezioni e documenti. Torino: Giappichelli editore, 2007, p. 286. SANTOS JUSTO, António. História do pensamento jurídico. Disciplina de Tópicos Especiais - Programa de Pós-graduação em Direito Unisinos. São Leopoldo: Unisinos, 2005, p. 15.

74 WIEACKER, Franz. op.cit.,p. 313.

75 WIEACKER, Franz. op. cit., p. 279 e segs.

76 MOSCATI, Laura. Insegnamento e scienza giuridica nelle sperienze italiane preunitarie. In: LIOTTA, Filippo. Studi di storia del diritto medioevale e moderno. Bologna: Monduzzi Editore, 1999, p. 290-1.

77 SANTOS JUSTO, António. op. cit., p. 15. 
meios, garantindo a renovação científica do direito, como queriam alguns historicistas, levaria à perda da compreensão da realidade social e poria o movimento em forte contradição ${ }^{78}$.

Nesse sentido, torna-se imprescindível reconhecer, em algum grau, uma espécie de conformação do historicismo jurídico encabeçado por Savigny a algumas teses notadamente atreladas à Escola Pandectista, haja vista que se valeu de determinadas concepções fortemente dispostas no direito romano para serem adequadas às especificidades da cultura alemã; e também à epistemologia kantiana, na medida em que considerou o conhecimento como rigorosamente racional para que fosse possível a justificação da segunda função da ciência jurídica, isto é, a precisão do momento científico ${ }^{79}$.

Cabe reconhecer que o pensamento jurídico construído por Savigny trouxe uma forte carga de cultura clássica às estritas ideias pragmáticas desenvolvidas pela Göttingen Aufklärer, sobretudo a respeito das especificidades empiristas que compunham o método histórico comparativo ${ }^{80}$. Ou melhor, tendo em vista a influência não somente de Möser e Hugo, mas também de Herder e Burke, Savigny promoveu o amoldamento da compreensão de tradição a determinadas concepções romanistas a respeito do direito ${ }^{81}$.

O que notadamente ocorreu foi um amplo descompasso dentro da própria Escola Histórica em relação ao entendimento da ideia de tradição histórica, pois, na medida em que, para uns - Romanistas - a tradição se referia àquela cultivada pelos juristas alemães dos séculos tardo-medievais e modernos, portanto, colhida da concepção de direito comum; para outros Germanistas -, a tradição vinha compreendida pelo costume alemão e estava vinculada às leis germânicas alto-medievais. ${ }^{82}$

Assim, enquanto Savigny e seus seguidores Romanistas reconheceram cada sociedade como um organismo em que o direito se desenvolvia a partir de uma operação interna e silenciosa de poderes, cujo papel do jurista consistia em compreender a cultura jurídica que provinha da tradição romana para, posteriormente, regenerá-la em compasso com as especificidades locais; a visão Germanista, promovida pelo pragmatismo desenvolvido em Göttingen ${ }^{83}$, acreditava que a sociedade era uma larga inter-relação de interesses e o direito se compunha, arbitrariamente, a partir desse processo.

Não bastava articular juridicamente aquilo que era compreendido como tradição. Era necessário, em primeiro lugar, perceber a tradição como projeto vinculado à história de um povo, para, posteriormente, articular o direito como elemento fundamental da realização humana, presente em todo e qualquer aspecto das inter-relações pessoais ${ }^{84}$.

À parte suas discussões internas, o movimento histórico, cujo escopo metodológico visava impulsionar a união do racional ao objetivo, vinculou o direito à historia e à sociedade, compreendendo-o, desse modo, como o meio apto para realizar a conexão do envolvimento dos cidadãos com o Estado e, além disso, para promover os valores culturais da nação.

Porém cabe considerar que a meticulosidade das pesquisas empírico-históricas promovidas por dois dos mais importantes Germanistas da época, Georg Beseler e Jakob Grimm, a respeito das peculiaridades econômicas e geográficas que influenciavam o direito privado alemão, possibilitou o desenvolvimento de futuras análises político-institucionais ligadas à ideia do direito como artefato da cultura ${ }^{85}$.

Com o reconhecimento da tese Germanista - e o seu consequente estímulo de identificar e de conjeturar a ordem jurídica a partir das derivações sociais que a determinavam -, mas especialmente pelas novas contribuições de Rudolf Jhering, cuja reestruturação do pensamento se direcionou ao encontro de uma harmonia entre análise jurídica e justificação sociológico78 WIEACKER, Franz. op.cit., p. 312-13.

79 WHITMAN, James Q. The Legacy of Roman Law in the German Romantic Era. Princeton: Princeton University Press, 1990, p. 215 e segs. WIEACKER, Franz. op. cit., p. 303 e segs. SANTOS JUSTO, Antônio. op. cit., p.15.

80 SCHIOPPA, Antonio Padoa. Storia del diritto in Europa: dal medioevo all'età contemporanea. Bologna: Mulino, 2007, p. 506.

81 PEARSON, Heath. op. cit, p.28-9

82 SCHIOPPA, Antonio Padoa. op. cit., p.505.

83 IGGERS, George G. op. cit., 16-7.

84 PEARSON, Heath. op. cit, p.28-9.

85 PEARSON, Heath. op. cit, p.28-9. 
pragmática, foi que o aspecto dado às análises de direito privado mudou gradativamente de rumo; ou seja, as análises passaram a reconhecer, a absorver e a incorporar, notoriamente, o intrínseco caráter social assumido pela propriedade e, a partir disso, a se edificar em conformidade dessa necessária consideração ${ }^{86}$.

A relevância da dimensão não absoluta do direito de propriedade - determinada pela sua imprescindível justificação perante o contexto social em enfoque - atraiu cada vez mais o interesse jurídico pela análise econômica das instituições, bem como estimulou o modo de pensar econômico às especificidades dos círculos em que outrora eram considerados estritamente jurídicos.

Na Inglaterra, Henry Sumner Maine - um dos responsáveis pela expansão dos fundamentos da Escola Histórica Alemã, sem, contudo, acolher aquela fé romântica no Volksgeist, porém fortalecido de uma aproximação comparativa e antropológica -, apontou em direção da importância de se considerarem as opiniões e as necessidades de cada contexto social para a construção de um adequado sistema jurídico ${ }^{87}$.

Segundo Maine ${ }^{88}$, as sociedades progressistas, suas necessidades e opiniões, se assentavam sempre avante ao direito, portanto discutir historicamente as instituições, segundo ele, mostrava-se de fundamental importância para que fosse possível compreender juridicamente o estado em que se encontrava cada situação particular.

Como os demais estudiosos daquele tempo, o autor inglês já não mais se filiava à possibilidade de as categorias desenvolvidas pelo direito clássico serem capazes de explicar, de forma satisfatória, a evolução jurídica à sociedade. Ou seja, ele acreditava no progresso civilizacional como meio apto a colocar o direito civil como guardião das obrigações individuais e romper com o seu fundamento clássico de dependência familiar baseada no conceito de status.

Unir a possibilidade de dar um tratamento histórico às ciências, sem deixar de resguardar e fortalecer a sua capacidade explicativo-racional, fez com que o movimento historicista, em algum grau, respondesse aos anseios políticos europeus datados da segunda metade do século XIX, incorporando à ordem jurídica as instâncias sociais e favorecendo a compreensão da realidade dinâmica do direito sem, contudo, deixar de defender a ordem liberal burguesa.

Era necessário, para tanto, estabelecer princípios originais - ultrapassando as antigas fórmulas da filosofia crítica que se encontravam vinculadas à concepção de liberdade absoluta - que trouxessem consigo, sobretudo, uma adequada proposta de (re)construção, garantindo, ainda e especialmente, a manutenção do sistema capitalista ${ }^{89}$.

Dito de outro modo, mostrava-se determinante repensar a ideia moderna de direito subjetivo que colocava a coisa à sombra do proprietário na sua plenitude abstrata e individuada - para poder abarcar a diversidade fenomenológica que se criava ${ }^{90}$.

A pureza estática da propriedade edificada sobre o indivíduo e para o indivíduo teve de ser reestruturada, isto é, não mais pode partir do velho sujeito de direito civil - liberado de qualquer impacto econômico ou social -, mas sim dela mesma, da coisa, reconhecendo toda a concretude estrutural que the compunha e a sua própria realidade dinâmica ${ }^{91}$.

O Estado, resignando-se em face de seus novos corolários científicos, da natureza e do papel do direito ${ }^{92}$, buscou colocar o proprietário diante da necessidade de prestar contas a determinadas exigências funcionais - especificidades econômicas e sociais -, fazendo com que se complexificassem as bases uma vez postas pela(s) teoria(s) do contrato social.

A ciência ali em voga tinha sua força no triunfo do método comparativo, cuja realização

86 PEARSON, Heath. op. cit, p.28-9. WIEACKER, Franz. op. cit., p.357.

87 MAINE, Henry Sumner. The effects of Observation of India on Modern European thought. USA: Folcroft Library Editions, 1974.

88 MAINE, Henry Sumner. Ancient Law: Its Connection with the Early History of Society and Its Relation to Modern Ideas. Boston: Beacon, 1963, p. 15 e segs.

89 INGRAM, John Kells. op. cit., p. 79.

90 GROSSI, Paolo. Proprietà e contratto. In: FIORAVANTI, Maurizio. Lo Stato Moderno in Europa. Roma-Bari: Laterza, 2002, p. 133 e segs.

91 GROSSI, Paolo. op. cit., p. 133 e segs.

92 KELLY, John. M. Storia del Pensiero Giuridico Occidentale. Bologna: Mulino, 1996, p. 380. 
se evidenciava pelo interesse recíproco que se difundira, amplamente, entre as disciplinas de direito e a economia93.

Nessa mesma perspectiva ganhou notoriedade a obra De la propriété et des sés formes primitives, de 1874, escrita pelo autor franco-belga Émile de Laveleye, na qual pôs em destaque o evolucionismo social das instituições, enfatizando que as diferentes formas assumidas pela propriedade ao logo dos tempos denunciara a consequente tendência do caráter progressivo e reformador do direito ${ }^{94}$.

A concepção de Laveleye recebeu a admiração de Adolph Wagner, representante do que se pode chamar de a segunda leva de pensadores da German Historical School of Economics, em cuja obra Fundation of Economics, de 1876, levou ao fim e ao cabo a proposta de uma ciência econômica do direito, na medida em que acreditava na possibilidade de uma séria análise da vida econômica da comunidade para a compreensão e a determinação do âmbito da liberdade econômica individual ${ }^{95}$.

Ambos defendiam que o direito claramente não poderia ser considerado como um produto arbitrário vinculado a meros desejos humanos, todavia acreditavam que a esfera jurídica vinha composta como consequência de um emaranhado de questões que se revelavam acordadas: por um lado, às imbricações econômicas da sociedade; por outro, às diferentes concepções de justiça derivadas do sistema moral/religioso ${ }^{96}$.

Claramente se nota a forte influência dos teóricos socialistas já nessa segunda leva de pensadores da Escola Histórica, como, por exemplo, Proudhon, Lassalle, Marx, Engels, etc. ${ }^{97}$, haja vista que foram eles os responsáveis por dar o primeiro impulso à ideia de que a posição econômica individual dependeria, necessariamente, da existência de um sistema (jurídico) apto a organizar a propriedade privada.

Apesar de toda a divergência ideológica existente entre os socialistas e a corrente historicista, na medida em que os pensadores históricos não acreditavam, como aqueles, na tese da onipotência do Estado, cujo único fim seria promover a transformação radical e imediata da composição econômica da sociedade em benefício da classe operária, foi inegável a convergência de ambos em alguns pontos de vista, sobretudo quanto à intervenção do domínio público no moderno sistema industrial, que colocava sob pressão as camadas menos favorecidas da sociedade.

Inclusive, por volta do último quarto do século XIX, os pensadores alemães, por defenderem uma mudança sistemática e gradual da concepção do direito de propriedade que fosse ao encontro e considerasse as novas questões sociais em voga, foram rotulados pelos partidários do free-trade como defensores de uma nova forma de socialismo ${ }^{98}$, tão perigosa quanto aquela vertente revolucionária.

Entretanto o que na verdade ocorria, em vez disso, era o reconhecimento e a defesa de um novo pensamento, de um novo método científico, tendo em vista a necessidade de reforma do sistema, que influenciaria e aproximaria, por consequência, as concepções de direito e economia, sem deixar obviamente de trazer consigo certa carga político-ideológica, isto é, do que se pode chamar de uma reforma proveniente do alto, cujo resultado foi a fortificação de um estado-intituição racional-burocrático ${ }^{99}$.

Noutras palavras, as características reformadoras da Escola Histórica não romperam com as bases do pensamento do primeiro liberalismo, isto é, reconhecer e implementar as questões sociais no regime liberal seria somente o corolário da efetividade do método histórico, que reconhecia no capitalismo o modelo econômico, mas compreendia inadequado o seu método científico.

Para manter o presente regime capitalista, era necessário adaptá-lo a um caráter social, com um método científico condizente às suas necessidades. E mais: uma reforma social eficiente traria uma legitimação sociológica à democracia constitucional daquela época ${ }^{100}$.

93 PEARSON, Heath. op. cit., p. 30-1.

94 PEARSON, Heath. op. cit., p. 34.

95 INGRAM, John Kells. op. cit., p. 87.

96 INGRAM, John Kells. op. cit., p. 83 e segs.

97 INGRAM, John Kells. op. cit., p. 84.

98 INGRAM, John Kells. op. cit., p. 84.

99 RITTER, Gerhard. Storia dello Stato sociale, op. cit., p.79.

100 RITTER, Gerhard. Storia dello Stato sociale, op. cit., p.71. 


\section{CONSIDERAÇÕES FINAIS}

Enquanto alguns seguiam os passos do socialismo por meio de uma revolução imediata, como queria Marx e seus seguidores, rompendo com o sistema capitalista; outros propunham uma simples reforma das instituições, que, por meio de uma reviravolta lenta e gradual, revitalizaria o próprio sistema político liberal.

Reformar o sistema capitalista para mantê-lo vivo e fortificado. Tal pressuposto somente seria possível se não ultrapassasse a legitimidade das instituições jurídico-políticas. Ou melhor, tal pressuposto somente seria possível especialmente por meio da extensão da legitimidade das instituições jurídico-políticas, o que, como resultado, traria a caracterização da função econômica das instituições e a compreensão de que a economia política seria a fundamentação de todas as ciências sociais ${ }^{101}$.

Assim, a proposta da Escola Histórica se mantinha em um meio-termo: considerava os abusos econômicos do sistema liberal, reconhecia a necessidade de incorporar as questões sociais aos discursos jurídicos, políticos e econômicos, contudo as mudanças deveriam ser pensadas dentro do sistema, não por meio de uma ruptura revolucionária.

O máximo que se poderia chegar era reformar, e para se alcançar tal máximo se mostrava imprescindível um novo método que conseguisse vincular as condições econômicas da sociedade às consequências do direito de propriedade, ou seja, fazer convergirem as disciplinas de direito e a economia para rearticular o papel do Estado e assim apontar em direção da possibilidade/ necessidade de uma completa ciência da sociedade. Nada teria podido expor de melhor forma essa síntese do que a disciplina reconhecidamente intitulada Ciência do Estado (Staatswissenschaft).

\section{REFERÊNCIAS}

ASCHERI, Mario. Introduzione storica al diritto moderno e contemporaneo: lezioni e documenti. Torino: Giappichelli editore, 2007.

BACON, Francis. Ensaios. 3. ed. Lisboa: Guimarães editores, 1992.

BARROW, Clyde. When Political Science Was Not a Discipline: Staatswissenschaft and the Search for a Method of Economic Interpretation. Annual meeting of the Western Political Science Association. Marriott Hotel, Portland, Oregon, Mar 11, 2004. Disponível em: http://www.allacademic.com/meta/ p88082_index.html.

BOBBIO, Norberto. Dalla struttura alla funzione. Nuovi studi di teoria del diritto. Bari: Laterza, 2007.

BOBBIO, Norberto. Liberalismo e Democrazia. Milano: Simonelli Editore, 2006.

BOBBIO, Norberto. Prefazione. In: FERRAJOLI, Luigi. Diritto e ragione. Teoria del garantismo Penale. 8.ed. Roma-Bari, 2004.

BLOCH, Ernest. Diritto naturale e dignità umana. Torino: Giappichelli Editore, 2005.

BURROW. J. W. Evolution and Society. Cambrigde: Cambridge University Press, 1966.

CAPPIELLO, Stefano. L'interazione tra economia e diritto. In: CIOCCA, Pierluigi; MUSU, Ignazio. (a cura di). Economia per il diritto. Torino: Bollatti Boringhieri, 2006.

COSTA, Pietro. Lo Stato di diritto: un'introduzione storica. In: COSTA, Pietro; ZOLO, Danilo. Lo stato di diritto. Storia, teoria e critica. 3. ed. Milano: Feltrinelli, 2006.

DESCARTES, René. Discurso sobre o método. Bauru. Edipro, 1996.

FERRAJOli, Luigi. Principia iuris. Teoria del diritto e della democrazia. 2. Teoria della democrazia. Roma-Bari: Laterza, 2007.

101 LORIA, Achille. Economic Foundations of Society. London: Swan Sonnenschein and Co., 1899, p. 118. 
FERRAJOLI, Luigi. Diritto e ragione: Teoria del garantismo Penale. 8. ed. Roma-Bari, 2004.

FIORAVANTI, Maurizio. Costituzione. Bologna: Il Mulino, 1999.

GERBER, Carl Friedrich Wilhelm Von. Sui diritti pubblici e Lineamenti di diritto pubblico tedesco. In: Diritto pubblico. Milano: Giuffrè, 1971.

GOZZI, Gustavo. Democrazia e diritti. Germania: dallo Stato di diritto alla democrazia costituzionale. 2. ed. Roma-Bari: Laterza, 2003.

GROSSI, Paolo. Proprietà e contratto. In: FIORAVANTI, Maurizio. Lo Stato Moderno in Europa. RomaBari: Laterza, 2002.

HOBSBAWM, Eric J. Il trionfo della borghesia. 1848-1875. 2. ed. Roma-Bari: Laterza, 2006.

HöFFE, Otfried. O que é justiça? Porto Alegre: Edipucrs, 2003.

IHERING, Rudolf Von. A luta pelo direito. 5. ed. São Paulo: RT, 2008.

IHERING, Rudolf Von. El espiritu del Derecho Romano. Oxford: Oxford University Press, 2001.

INGRAM, John Kells. A History of Political Economy, 1888. Disponível em: http://www.dominiopublico. gov.br/pesquisa. Acesso em: 15/09/2009.

IGGERS, George G. New Directions in European Historiography. Middletown: Wesleyan University Press, 1975.

KELLY, John. M. Storia del Pensiero Giuridico Occidentale. Bologna: Mulino, 1996.

LOCKE, John. The Works of John Locke in Nine Volumes. 12. ed. London: Rivington, 1824. Em especial vol. 4. Disponível em: http://oll.libertyfund.org/title/763. Acesso em: 15/04/2009.

LORIA, Achille. Economic Foundations of Society. London: Swan Sonnenschein and Co., 1899.

MACKAAY, Ejan. History of Law and Economics. In: BOUCKAERT, Boudewijn and DE GEEST, Gerrit, Encyclopedia of Law and Economics, Volume I. The History and Methodology of Law and Economics, Cheltenham, Edward Elgar, 2000.

MAINE, Henry Sumner. The effects of Observation of India on Modern European thought. USA: Folcroft Library Editions, 1974.

MAINE, Henry Sumner. Ancient Law: Its Connection with the Early History of Society and Its Relation to Modern Ideas. Boston: Beacon, 1963.

MATTEUCCI, Nicola. Organización del Poder y Libertad: Historia del Constitucionalismo Moderno. Madrid: Trotta, 1998.

MARX, Karl. Il capitale. Critica dell'economia politica. 4. ed. Roma: Newton, 2008.

MARX, Karl; ENGELS, Friedrich. Manifesto do partido comunista. Disponível em: file:///Cl/site/livros_gratis/manifesto_comunista.htm, 2001.

MARX, Karl. Para uma crítica da economia política. Disponível on-line em: LivrosGrátis/paraumacritica.htm.

MERCURO, Nicholas; MEDEMA, Steven G. Economicsand the Law: from Posner to Post-Modernism. New Jersey: Princeton University Press, 1999.

MILL, John. The Principles of Political Economy with some of their applications to social philosophy. Disponível on-line em: http://www.ecn.bris.ac.uk/het/mill/prin.htm.

MOSCATI, Laura. Insegnamento e scienza giuridica nelle sperienze italiane preunitarie. In: LIOTTA, Filippo. Studi di storia del diritto medioevale e moderno. Bologna: Monduzzi Editore, 1999

MUSU, Ignazio. Pensiero economico e diritto. Più teorie economiche, ma terreni comuni. In: CIOCCA, Pierluigi; MUSU, Ignazio. (a cura di). Economia per il diritto. Torino: Bollatti Boringhieri, 2006. 
NUNES, António José Avelãs. Uma Introdução à Economia Política. São Paulo: Quartier Latin, 2007.

PEARSON, Heath. Origins of Law and Economics: the economists'New Science of Law, 18301930. Cambridge: Cambridge University Press, 1997.

RITTER, Gerhard A. Storia dello Stato sociale. 2. ed. Roma-Bari: Laterza, 2007.

RODOTà, Stefano. Il diritto terribile. Studi sulla proprietà privata. 2. ed. Bologna: Mulino, 1990.

ROLL, Eric. A History of Economic Thought. Oxford: Alden Press, 1973.

SANTOS JUSTO, António. História do pensamento jurídico. Disciplina de Tópicos Especiais - Programa de Pós-graduação em Direito Unisinos. São Leopoldo: Unisinos, 2005.

SAVIGNY, Friedrich Carl von. La Vocazione del nostro Secolo per la Legislazione e la Giurisprudenza. Bologna: Forni, 1968.

SAY, Jean-Baptiste. A Treatase on Political Economy; or the Production, Distriution, and Consumption of Wealth. Canadá: Batoche Books, 2001.

SCHIOPPA, Antonio Padoa. Storia del diritto in Europa: dal medioevo all'età contemporanea. Bologna: Mulino, 2007.

SMITH, Adam. La ricchezza delle nazioni. 2. ed. Roma: Newton Compton Editori, 2005.

WHITMAN, James Q. The Legacy of Roman Law in the German Romantic Era. Princeton: Princeton University Press, 1990.

WEACKER, Franz. A History of private Law in Europe with particular reference to Germany. Oxford: Oxford University Press, 1995. 